bave grown rapidly, and although at the necropsy it seemed possible to have removad it by operation, I do not think that a surgeon would have been justified in the attempt in so young an infant, especially when he could have no certainty as to the nature, extent, and connexions of the tumour.

MASSAGE AS A CURATIVE AGENT.

BY T. Geratd GarRY, M.D., M.CH., M.A.O.

THE following cases may be of interest as showing the value of massage where medicines are comparatively powerless.

CASE 1,-Mrs. A--, aged thirty-seven, with a decided nourotic history, for the past twelve months had been gradually losing weight and strength, and when first seen presented an emaciated and very anæmic appearance. She complained of weariness along the spine, which was worse in the morning and evening, but did not at any time amount to actual pain. Pressure on the tips of the vertebræ caused no discomfort, except at one well-defined spot in the lower part of the cervical region. Here deep pressure caused slight pain. The patient also complained of a feeling of numbness and burning in the right hand and forearm, which was much paler in colour than the left. These feelings commenced in the fingers, and gradually extended upwards until the forearm became involved, and after this no further progress was made, and the disease remained quiescent for a time, when the same sensations showed themselves in the left hand, but never amounted to very much. Both hands retained their normal power, and no alteration was noticeable beyond the paleness of the right arm already alluded to, and which no amount of friction could alter. This lady enjoyed very good health until about twelve months ago, and attributes her present ill health to domestic troubles. When first seen she was listless and depressed, and presented a very anæmic and careworn appearance. There was no hereditary history, nor was there any history of constitutional disease. She had been taking medicines for a long time, but without any apparent benefit. These were now dispensed with altogether, and the patient was placed under the massage treatment, under which she rapidly got well; indeed, an improvement was experienced from the first week. Special attention was directed to the spine, and whilst this part was "rubbed" the feet were placed in medicated water. She is now quite strong, and feels perfectly well in every way.

CASE 2--Mrs. B - - aged thirty-five, for the past few years had been rapidly gaining in weight, and when first seen weighed $14 \mathrm{st}$. $4 \mathrm{lb}$. During this time her health had become very much deteriorated, and the slightest exertion, even walking along a perfectly level ground, was only accomplished with difficulty. The muscles were weak and flabby; the heart sounds were weak and the pulse almost imperceptible. She was often seized with faintness, and these attacks were usually preceded by intense pain in the region of the heart, which was relieved by deep pressure. Thirst was a prominent symptom, and it was always worse at night-time. Urine normal, except that it occasionally contained a trace of sugar. There was every indication of the nervous system being at fault, and the patient was told by a well-known London physician that it was in a most impoverished state, and recommended that she should go abroad for two years. "All kinds of medicines" had been tried without benefit, and lately she had on her own recommendation taken large quantities of some patent drug reputed to diminish corpulency. It had the desired effect, but on its cessation the weight of course increased again. An interesting point in connexion with this case is the fact that under the influence of mental anxiety and worry the weight rapidly increased; indeed, on a few occasions I have known her to gain as much as a pound and a half daily when the mental strain was very great. On the other hand, prolonged rest had the effect of diminishing the weight, whilst even very moderate exercise had an opposite effect. These facts fully demonstrate the neurotic nature of the case, and have an interesting bearing on somepoints recently brought forward concerning the management of neurasthenic subjects. Massage was employed three times a week, each sitting at first lasting half an hour. After a few weeks it was used daily. The patient's condition commenced to improved after the first fortnight. It ought to be mentioned that at the commencement of the treatment the patient had very little faith in " the rubbing," having already tried it in London and Brighton, but it effected nothing beyond a few intractable bruises. The method now employed was first introduced into this country by Dr. J. F. Little, of Welbeck-street, and is exactly the same as practised by Weir Mitchell at Philadelphia. Besides the massage, the patient was allowed a Russian bath occasionally. In suitable cases they are very useful adjuncts. After a little more than four months the patient lost $2 \mathrm{st} .3 \mathrm{lb}$., and gained wonderfully in strength. The heart sounds are strong, and pain has long since disappeared. She is now capable of walking many miles without feeling exhausted; and, although the massage has been discontinued for a considerable time, there has been no increase in the weight, but, on the contrary, a slight diminution.

\section{NASAL CATARRH AND APROSEXIA.}

By R. Hingston Fox, M.D., M.R.C.P.

DR. GUYe of Amsterdam has applied the term "Aprosexia" ( $\alpha$, priv., and $\pi \rho \sigma \sigma \epsilon \epsilon \epsilon \nu$, to apply) to the symptom of inability to fix the attention on any subject - a kind of mental lassitude. He points out the association of this with nasal affections, both acute and chronic. The explanation is offered that the lymphatics passing from the anterior part of the brain into the nasal fossa become more or less choked, and hence there is exhaustion of the cerebral centres from retention. ${ }^{1}$ Some experience, objective and subjective, of severe nasal catarrbs has familiarised me with this symptom. The inability to fix the attention is attended with depression of spirits and a feeling of prostration, sometimes intense. Meantime the temperature is subnormal and the pulse quiet. Probably the symptoms are most marked in cases where, as usually in recurrent catarrh, ther $\ni$ are some chronic changes in the nasal passages. In a recent case the theory above stated suggested a means of relief. Acting on Dr. H. G. Sutton's teaching of helping the lymphatic circulation by free respiration, the patient, though unwilling to leave his bed, was made to go out and walk steadily up hill. The freer play of the lungs seemed to bring marked mental relief; doubtless the directly stimulating effect of fresh air had also a share in the benefit. Of the various abortive treatments for nasal catarrh, I have tried repeatedly aconite in ten minute doses, cubeb cigarettes, and instillation of cocaine. Each of these seemed to cure in some instances; in others the cold pursued its course unchecked. Change of air and Easton's syrup I find very beneficial.

\section{CASE OF PITYRIASIS RUBRA ACUTA.}

BY M. J. T. J. BLaNCARD, SURGEON, MADRAS ARMY.

A NATIVE, aged thirty-four, came under my care on Aug. 4th, 1887, complaining of heat and pain about the nape of the neck and the joints of the fingers and toes. The tongue was covered with whitish fur on the dorsum, and was red at the edges. Temperature $99^{\circ} 5^{\circ}$. Great exhaustion and inability to move were complained of on the 6th. The knees were swollen, and fluctuation was distinctly felt on palpation. The knee reflexes were exaggerated, anorexia was obstinate, and in the morning the temperature had increased to $1015^{\circ}$. The skin over the whole body was covered with copper-coloured patches, slightly raised and smooth, giving a sensation of elasticity to the touch. The bowels were fairly regular. The temperature in the morning reached $1026^{\circ}$. On the 7th the patches which had appeared the day before had extended excentrically, and crops of minute papules of light colour had now made their appearance on the patches, giving a sensation as if shots had been scattered over the surface and there adhered. These papules did not merge into vesicles, but they increased in size till they coalesced with the other papules and formed elevated islets, which after four days dried up and deequamated in large flakes, leaving the dermis exposed, smooth, and shiny. The scalp was also affected, and loss of hair followed. The nails were all shed on the eighteenth day of the disease, the whole desquamative process taking nearly a month from the papular eruption till the time when the nails and hair 
began to appear. During the whole course of the disease fever was constant, but the temperature never rose above $1026^{\circ}$. The treatment adopted was chiefly directed towards obviating the malarial tendency of the patient, who had suffered much from ague-not, however, directly preceding the present attack. Quinine in five-grain doses, combined with three minims of liq. arsenicalis, was given three times daily, with milk diet. The local treatment consisted of frequent applications of cocoanut and petroleum (crude) oils on lint.

\section{d. âthroror}

\section{OF}

\section{HOSPITAL PRACTICE, BRITISH AND FOREIGN.}

Nulla autem est alia pro certo noscendi via, nisi quamplurimas et morborum et dissectionum historias, tum aliorum tum proprias collectas habere, et inter se comparare.-MoraAGI De Sed. et Caus. Morb. lib. iv. Procmium.

\section{MIDDLESEX HOSPITAL.}

THREE CASES OF HYSTERECTOMY; REMARKS.

(Under the care of Mr. Henry Morris.)

THese three cases of hysterectomy for myomata and fibrocystic tumours of the uterus may be taken in conjunction with one recorded in the Hospital Mirror of THE LANCET, March 25th, 1885, and two others published in the same journal of Jan. $9 \mathrm{th}, 1886$, as representing the practice of one general surgeon in this department of surgery during three years. Two of the three patients whose cases are now recorded are alive and well, and though this unfortunately cannot be said of the third, still it may fairly be claimed that the third patient also recovered from the operation. This woman had, seven years before, undergone an operation wellnigh as severe, and to those who watched her through the second operation there was no doubt as to her convalescence from it, when she was exposed, and, so far as can be told in the absence of a post-mortem, succumbed to, an anomalous form of septicæmia excited by the contagion of scarlet fever. In addition to these cases Mr. Morris has operated in one other case during the year 1887-a private case. This lady was exceedingly corpulent, and had been brought into a very desperate condition of feebleness and breathlessness by the enormous tumour, complicated by fatty degeneration of her heart and voluntary muscles. The tumour was very soft and vascular, and much trouble was experienced at the operation from the lacerable nature and spongy softness of the tumour. The whole (tumour, fundus and supra-vaginal cervix, and uterine appendages) were removed and the operation satisfactorily concluded, but the patient rapidly sank after it. The abdominal muscles had undergone such complete fatty degeneration that they had a pale greasy appearance, were very lacerable, and had none of the characters of normal muscular tissue. For the following notes we are indebted to Mr. W. G. Nash, house surgeon.

CASE 1. Fibro-myoma of uterus; intestinal obstruction from pressure; hysterectomy; recovery.-M. S—, aged thirty-five, a cook, was admitted in the first instance under the care of Dr. Douglas Powell on Dec. 16th, 1886, complaining of a swelling in the lower part of the abdomen and obstinate constipation, amounting at times to complete obstruction. She stated that she had never been ill before. The catamenia had always been regular. She had lately suffered from menorrhagis. For some weeks her bowels had been very constipated, she had lost her appetite, and felt altogether ili.

On admission, the patient, a fair-haired, fairly wellnourished, anæemic woman, complained of headache, constipation, sickness and general weakness, and of some swelling in the abdomen. Pulse 80 , respiration 20 ; temperature $986^{\circ}$. On examination the abdomen was rather full. At the lower part, in the middle line, evidently extending upwards out of the pelvis, could be felt a large, hard, uniform swelling, oval in shape. This swelling was somewhat tender on palpation and dull on percussion. It was movable from side to side. Its upper limit was three inches beiow the umbilicus. The liver, spleen, and kidneys were all natural in size.
Urine normal. Well-marked uterine souffle was to be heard one inch to the left of the median raphe, and midway between the pubes and umbilicus. Per vaginam the cervix was found to be incorporated with the growth. The uterus was freely mobile. Diagnosis, myoma.

Dec. 27 th.-Abdominal tumour has increased in size, and the upper limit now reaches to the level of the umbilicus.

Jan. 3rd, 1887.--Bowels open for the first time for fourteen days. No diminution in the size of the tumour; if there is any change, it is one of increase in size.

6th.-Catamenia appeared.

10th.- The tumour has diminished in size, and is less tender since the appearance of the catamenia, which have been very profuse.

13th.-Tumour again increasing in size.

21 st. (Note by Dr. Edis.) - Dorsal decubitus. Uterus considerably enlarged, the fundus uteri being felt on a level with the umbilicus. Uterus mobile. Tumour enters brim of pelvis, but there is no impaction whatever. Cervix small and conical. Vterine sound passes upwards and forwards four inches.

Operation.--On Jan. 29th hysterectomy was performed by Mr. Morris. The abdomen was opened in the median line by an incision five inches long between the pubes and umbilicus. A single large smooth elastic tumour was exposed, free from adhesions. This tumour, which was growing from the back part of the uterus, was readily turned out of the abdomen with the uterus and its appendages Tait's clamp was applied around the cervix uteri, and the uterus, its appendages, and the tumour were removed. The pedicle, with the clamp, were brought out at the lower end of the incision, and the abdomen closed in the usual manner. The wound was dressed with iodoform wool The tumour removed weighed fifty-six ounces. It consisted of a single large fibro-myoma, growing in the posterior wall of the hypertrophied body of the uterus. The tumour was encapsuled, and on section presented the typical appearance of a fibro-myoma. The cavity of the uterus contained a little blood-stained mucus. The section appeared to have passed through the upper part of the cervix. Both ovaries were enlarged, scarred, and fibrous. On section, each contained six or more cysts about the siza of horse beans these cysts containing clear pale yellow fluid. Both Fallopian tubes were hypertrophied, but without fluid or other morbid contents. A fow small cysts were found at the fimbriated extremity of each of the tubes.

The patient did uninterruptedly well, and up to the twentyfirst day the temperature never rose above $99^{\circ} 4^{\circ}$. The clamp came away on the seventeenth day. The bowels acted for the first time after the operation on the ninth day. From the twenty-first to the twenty-eighth day the temperature varied from $1006^{\circ}$ to $102 \cdot 4^{\circ}$, but without any other symptom of constitutional disturbance. On the thirtieth day the temperature was normal. On the thirtysixth day she was removed to a general ward, and was discharged from the hospital quite well nine weeks from the date of operation. She came to the hospital to report herself six months after leaving, and was then in excellent health, and expressed herself as never having been better in health.

CASE 2.-Fibro-myoma of uterus; hysterectomy; recovery. P. W- aged forty, a single woman, was admitted under Mr. Morris on Fub. 16th, 1887, complaining of a swelling in the lower part of her abdomen, pain in the tumour and in the sacral region, floodings, and difficult micturition. She stated that the catamenia appeared at the age of fourteen, and continued regularly and normally until December, 1886, at which time she had a severe flooding, which lasted four weeks. In October, 1886, she noticed a Iump towards the right side of the hypogastrium about the size of a hen's egg. At the time of the flooding in December, she suffered from sharp pains in the region of the tumour, which had recurred at short intervals. She had also had several slight recurrences of the flooding. The tumour had continued to increase, and became larger between the floodings. For six weeks she had had occasional difficulty in emptying the bladder.

On admission the patient presented the appearance of a fairly nourished woman. There was evident bulging in the hypogastric and right iliac regions. On palpation a hard resisting mass could be felt rising out of the pelvis. The tumour extended upwards to two inches below the umbilicus, and laterally more to the right side. The surface was irregular, presenting several bossy projections. There 